\title{
Psychiatric morbidity in children with epilepsy
}

\author{
Fahmida Ferdous, ${ }^{1}$ Md Faruq Alam, ${ }^{2}$ Mohammad Muntasir Maruf, ${ }^{3}$ Shoebur Reza Choudhury, ${ }^{4}$ Md Mashukur \\ Rahman Chisty, ${ }^{5}$ Sayeda Afroza, ${ }^{6}$ Hariprakash Chakravarty ${ }^{7}$
}

${ }^{1}$ Assistant Professor, Department of Psychiatry, Z H Sikder Women's Medical College, Dhaka, Bangladesh; ${ }^{2}$ Professor and Director, National Institute of Mental Health (NIMH), Sher-E-Bangla Nagar, Dhaka, Bangladesh; ${ }^{3}$ Assistant Professor, Department of Psychiatry, Shaheed M Monsur Ali Medical College, Sirajganj, Bangladesh; ${ }^{4}$ Associate Professor, Department of Psychiatry, Sir Salimullah Medical College (SSMC), Mitford, Dhaka, Bangladesh; 5 Senior Lecturer, Department of Anatomy, Dhaka National Medical College, Dhaka, Bangladesh; ${ }^{6}$ Professor, Department of Paediatrics, SSMC, Mitford, Dhaka, Bangladesh; ${ }^{7}$ Chief Neurosurgeon and Medical Director, Z H Sikder Women's Medical College, Dhaka, Bangladesh.

$\begin{array}{ll}\text { Article info } & \\ \text { Received } & : 02 \text { Oct. } 2017 \\ \text { Accepted } & : \text { 27 Jan. } 2018 \\ \text { Number of tables } & : 02 \\ \text { Number of figures } & : 00 \\ \text { Number of refs } & : 12\end{array}$

Correspondence

Fahmida Ferdous

Mobile: +8801727324151

E-mail:ferdous_fahmida@yahoo.com

\begin{abstract}
Summary
Suffering from psychiatric illness is relatively common in epilepsy. There is now general agreement that incidence of neuro-behavioral disorders is higher in patients with epilepsy. The objective of the study was to find out the proportion of psychiatric disorders among the children suffering from epilepsy. It was a cross sectional study conducted during the period from July 2009 to June 2011 at the department of Paediatrics in Sir Salimullah Medical College and Mitford Hospital, Dhaka, Bangladesh. In the study 104 children, aged 5-16 years, having epilepsy were purposively included and patients with febrile seizure were excluded. Data were collected through face-to-face interview using a semistructured questionnaire and diagnosis of psychiatric disorders was assigned according to the Diagnostic and Statistical Manual of Mental Disorders, $4^{\text {th }}$ edition, text-revision (DSM-IV-TR). The results showed that among all patients $56.7 \%$ were male and $43.3 \%$ were female. Most of them $(80.8 \%)$ were within $5-10$ years of age. Among them, $57.7 \%$ of the cases had associated psychiatric disorders, where $21.2 \%$ had intellectual disability, 10.6\% communication disorder, $7.7 \%$ learning disorder, $6.7 \%$ major depressive disorder, 5.8\% ADHD and 1.9\% had autistic disorder. This study suggests that significant number of children with epilepsy has been suffering from psychiatric illnesses. So, during diagnosis of epilepsy, early psychological assessment should be done.
\end{abstract}

Bang J Psychiatry 2016;30(1):7-9

\section{Introduction}

Epilepsy is a neurological disease which usually starts at childhood and characterized by seizures, or a paroxysmal brain dysfunction due to excessive neuronal discharge with a lifetime prevalence of $1 \%$ to $2 \% .{ }^{1}$ It is the most common neurological disorder worldwide affecting an estimated 50 million people and $80 \%$ of affected children are estimated to live in low-income countries. ${ }^{2-4}$ Children with epilepsy have a high burden of psychiatric and neuro-developmental co-morbidities, and they experience poor long-term psychosocial outcomes even after remission of their epilepsy in adulthood. ${ }^{1,5}$ Epilepsy affects physical, mental and behavioral functions and is associated with higher risk of premature death due to traumatic brain injury, status epilepticus, suicide, pneumonia and sudden death, and it accounts for $1.4 \%$ of all years of life lost. ${ }^{3}$ There is now a general agreement that the incidence of neurobehavioral disorders is higher in patients with epilepsy than in the general population. ${ }^{6}$ Co-morbidities in epilepsy can be debilitating, but they are often overlooked. Fortunately, a number of recent efforts are increasing the attention to co-morbidities. ${ }^{7}$ Epilepsy has long been considered to be a risk factor for psychosis. ${ }^{8}$ There are also increased risks for developing other psychiatric co-morbidities. Though the increased prevalence of behavioral problems has often been documented in children with chronic seizures, several studies have also shown an increased prevalence of behavioral problems in children with new-onset or recent-onset seizures. Mitchell et al. (1994) followed up children for 18 to 30 months. They found that the severity of seizures and the prevalence of behavioral problems remained relatively stable over time. ${ }^{9}$ The aim of this study was to report the psychiatric co-morbidities among the children with epilepsy at a tertiary care hospital in Bangladesh.

\section{Materials and methods}

This cross sectional study was conducted during the period from July 2009 to June 2011 at the department of paediatrics in Sir Salimullah Medical College and Mitford Hospital, Dhaka, Bangladesh. A total of 104 children with epilepsy, aged 5-16 years, were enrolled consecutively in the study and patients with febrile seizure were excluded. Informed consent was taken from the parents or attending guardians before 
enrollment in the study. Diagnosis of epilepsy was confirmed by a neurologist. Then data were collected through face-toface interview using semi-structured questionnaire. Psychiatric assessment was done by psychiatrists working at the department of Psychiatry in SSMC and Mitford Hospital and diagnosis was assigned according to DSM-IV-TR. ${ }^{10}$ Data analysis was done by using SPSS (Statistical Package for Social Sciences) version 16.

\section{Results}

Among 104 enrolled children, 56.7\% were male and 43.3\% were female with male female ratio 1.3:1. Most of them (80.8\%) were 5-10 years of age and the rests were of 11-16 years. Family history of seizures was present in $4.8 \%$ cases. Regarding socio-economic condition, most (52.9\%) cases were from lower class (Table 1). Among all children $64.4 \%$ had partial seizures, $30.4 \%$ had absence seizures and $5.2 \%$ had generalized tonic clonic seizures. Among 104 studied cases majority (57.7\%) had associated psychiatric disorders. Among the disorders, most common (21.2\%) was intellectual disability (Table 2).

Table 1: Distribution of socio-demographic variables of the respondents $(n=104)$

\begin{tabular}{lcc}
\hline Socio-demographic variables & Frequency & Percentage \\
\hline Age in years & & \\
$5-10$ & 84 & 80.77 \\
$11-16$ & 20 & 19.23 \\
Sex & & \\
Male & 59 & 56.73 \\
Female & 45 & 43.27 \\
Habitat & & \\
Urban & 42 & 40.38 \\
Rural & 62 & 59.62 \\
Socio-economic condition & & \\
Upper & 12 & 11.54 \\
Middle & 37 & 35.58 \\
Lower & 55 & 52.88 \\
\hline
\end{tabular}

Table 2: Types of psychiatric disorders among the children suffering from epilepsy $(n=104)$

\begin{tabular}{lcc}
\hline Type of disorders & Frequency & Percent \\
\hline No psychiatric disorder & 44 & 42.3 \\
Intellectual disabilities & 22 & 21.2 \\
Attention-Deficit/Hyperactivity disorder & 6 & 5.8 \\
Autistic disorders & 2 & 1.9 \\
Learning disorders & 8 & 7.7 \\
Communication disorders & 11 & 10.6 \\
Major depressive disorder & 7 & 6.7 \\
Others & 4 & 3.8 \\
\hline
\end{tabular}

\section{Discussion}

The psychiatric co-morbidities in people with epilepsy have important clinical and therapeutic implications. There are few population-based studies evaluating the prevalence of psychiatric conditions in people with epilepsy. Most studies involve selected groups of patients from tertiary centers or specialized clinics. In our study, $57.7 \%$ of the cases had associated psychiatric disorders. Dharmadhikari and Sinha found the prevalence of psychiatric co-morbidity as about $31 \% .{ }^{11}$ Another study found that psychiatric disorders affect $41 \%$ patients with epilepsy. ${ }^{3}$ The difference can be explained by the differences in study setting and sample size distribution. In our study attention deficit hyperactivity disorder (ADHD) was found in $5.8 \%$ of the respondents. Attention problems can be influenced by epileptiform activity. ADHD appears to be prevalent among children who have received new diagnoses of epilepsy as well as in children who have chronic epilepsy. Other studies found that ADHD among children and adolescents with epilepsy, estimated between 12 to $39 \%$, is much higher than in the general population. ${ }^{12}$ Another study found ADHD in $2.67 \%$ of the respondents which was less than the findings of the current study. ${ }^{11}$ Depression in epilepsy is also very common, especially in patients with partial seizures of temporal lobe origin. In our study, it was found that $6.7 \%$ had major depressive disorder. Some authors mentioned depression as the most common psychiatric co-morbidity in epilepsy. ${ }^{7}$ Many hypotheses have been proposed to explain the relationship between depression and epilepsy. Some researchers found that seizures lead to increased susceptibility to depression by reducing expression of serotonin receptors. ${ }^{7}$ Other studies revealed that the common psychiatric co-morbidities found among patients with epilepsy were depression, neuroses (non-psychotic anxiety disorders) and psychoses. ${ }^{3}$ It has been observed that $25 \%-40 \%$ of individuals with certain neurological conditions such as epilepsy will develop a marked depressive disturbance and psychotic symptoms at some point during the course of illness. ${ }^{3}$ In our study, other co-morbidities included substance abuse, schizophrenia and social phobia. Some studies revealed the correlation between psychosis and epilepsy and found that the prevalence rate for psychosis in epilepsy patients was about $5.6 \% .^{8}$ Present study was conducted among the patients attended at a tertiary care hospital of Bangladesh and relatively smaller sample. So, studies covering the larger sample sizes, including multiple centers, evaluation of the community peoples, and assessment in primary care setting would be better to generalize the results.

\section{Conclusion}

The present study found that a quite significant number of children with epilepsy suffer from psychiatric disorders. Children with epilepsy need thorough evaluation by relevant 
health care providers for early diagnosis of those associated illnesses so that they can get more benefit besides the treatment of epilepsy. But, the study results do not reflect overall situation of the country. A broad based epidemiological study is needed to confirm the study findings.

\section{References}

1. Baca CB, Vickrey BG, Caplan R, Vassar SD, Berg AT. Psychiatric and medical comorbidity and quality of life outcomes in childhood-onset epilepsy. Pediatrics 2011;128(6):1532-43.

2. Burton K, Rogathe J, Hunter E, Burton M, Swai M, Todd J, et al. Behavioural comorbidity in Tanzanian children with epilepsy: a community-based case-control study. Dev Med Child Neurol 2011;53(12):1135-42.

3. Chang HJ, Liao CC, Hu CJ, Shen WW, Chen TL. Psychiatric disorders after epilepsy diagnosis: A population-based retrospective cohort study. PLoS One 2013;8(4):e59999.

4. Burton K, Rogathe J, Whittaker RG, Mankad K, Hunter E, Burton MJ, et al. Co-morbidity of epilepsy in Tanzanian children: a community-based case-control study. Seizure 2012;21(3):169-74.

5. Berg AT, Caplan R, Hesdorffer DC. Psychiatric and neurodevelopmental disorders in childhood-onset epilepsy. Epilepsy Behav 2011;20(3):550-5.
6. Dunn DW. Neuropsychiatric aspects of epilepsy in children. Epilepsy and behavior 2003; 4(2):101-6.

7. Brooks-Kayal AR, Bath KG, Berg AT, Galanopoulou AS, Holmes $\mathrm{GL}$, Jensen $\mathrm{FE}$, et al. Issues related to symptomatic and diseasemodifying treatments affecting cognitive and neuropsychiatric co morbidities of epilepsy. Epilepsia 2013;54:44-60.

8. Clancy MJ, Clarke MC, Connor DJ, Cannon M, Cotter DR. The prevalence of psychosis in epilepsy; a systematic review and meta-analysis. BMC Psychiatry 2014;14(1):9.

9. Mitchell WG, Scheier LM, Baker SA. Psychosocial, behavioral, and medical outcomes in children with epilepsy: a developmental risk factor model using longitudinal data. Pediatrics 1994;94:471-7.

10. American Psychiatric Association. Diagnostic and statistical manual of mental disorders. $4^{\text {th }}$ ed, text revision. Washington DC: American Psychiatric Association; 2000.

11. Dharmadhikari AS, Sinha VK. Psychiatric comorbidity in children with epilepsy: a cross-sectional 5 years rural prevalence study. J Neurosci Rural Pract 2017;8(2):179-84.

12. Gonzalez-Heydrich J, Dodds A, Whitney J, MacMillan C, Waber D, Faraone SV, et al. Psychiatric disorders and behavioral characteristics of pediatric patients with epilepsy and ADHD. Epilepsy Behav 2007;10(3):384-8. 